\title{
LÍRICA CHILENA DE FIN DE SIGLO Y (POST) MODERNIDAD NEOLIBERAL EN AMÉRICA LATINA
}

\author{
POR \\ JAVIER F. CAMPOS \\ Fairfield University
}

Nos interesa problematizar en este artículo los efectos de la acelerada modernidad consumista en cierta novísima poesía de Chile, especialmente la que comienza a escribirse desde mediados de los ochenta. Para ello es necesario establecer algunas importantes relaciones y diferencias entre dos promociones poéticas chilenas que temporalmente están distanciadas por casi veinte años. A su vez, reflexionar hasta donde resulta apropiado aplicar el controversial término "postmodernismo", "condición postmoderna" - términos que comienzan a usarse en América Latina desde mediados de los ochentas-para designar una producción cultural-artística chilena posterior a 1980, principalmente la que comienza a ser afectada por el plan de modernizaciones de la dictadura militar. ${ }^{1}$

La primera de esas dos promociones poéticas es la que corresponde a la promoción de los sesenta de la cual tomaremos ejemplos de la primera poesía de Gonzalo Millán, escrita a partir de 1966. La segunda es la promoción post-1973, aquella basta y heterogénea producción que se escribe bajo la dictadura militar; pero con especial atención en la poesía de ciertos novísimos quienes hacia 1985 comienzan a publicar una novedosa producción poética y cuya edad de ellos aún no llegaba en ese entonces a los treinta años. De lo anterior señalado, y que desarrollaremos más adelante, desprenderíamos la siguiente conclusión tentativa. Los términos "postmodermo" o "postmodernismo" o "condición postmoderna" al ser aplicados mecánicamente a la realidad chilena y latinoamericana en general - a partir de mediados de los ochenta - llegarían a ser, para una importante crítica

\footnotetext{
${ }^{1}$ Véase Patricio Rozas y Gustavo Marín, 1988: El "Mapa de la extrema riqueza" 10 años después.(Santiago, Chile: CESOC, 1989). Citamos lo siguiente de este texto: "La expansión de los grupos transnacionales, especialmente a partir de la crisis de 1981-1983, ha provocado modificaciones sustanciales en la relación entre capital transnacional y las clases dominantes locales ..." (283); “... el traspaso masivo de empresas, ocurridas principalmente después de 1985, revelan la existencia de una nueva fase de centralización del capital en la economía chilena, cuyos principales beneficiarios son algunas grandes corporaciones financieras multinacionales ... el análisis de los 24 grupos económicos de origen multinacional activos en Chile permite afirmar que su expansión ha provocado una profunda desnacionalización de la economía chilena, reforzándose el carácter dependiente de nuestra economía ...”(9 y 284); “... a partir de 1991 las utilidades de estos grupos transnacionales en Chile se elevará a más de mil millones de dólares anuales” (285).
} 
latinoamericana actual, términos más o menos confusos en relación a la justificación que se les ha dado en las sociedades de verdadera condición postmoderna o post-industrial, condición que nuestro continente está lejos de poseer. ${ }^{2}$ Porque nuestra verdadera y real condición es que en América Latina en los ochentas comienza un proceso extremo de transnacionalización como recientemente han señalado algunos destacados sociólogos latinoamericanos. ${ }^{3}$ Esta agudización mucho más compleja de nuestra ya conocida condición de dependencia, unida ahora a la profusión de un sofisticado mercado de mensajes y la producción de subjetividad por la cultura de la imagen, incomparable a la década de los cincuenta y de los sesenta, constituye una razón bastante válida para que se estén produciendo nuevos contenidos y una reactualización de renovadas formas en el discurso poético de los más jóvenes - según específicas zonas del continente. Sin embargo algunas de aquellas formas (montaje intertextual, experimentalismos y rupturas variadas, etc.) ya habían aparecido en la vanguardia de los 20-30 y también re-emergieron bien dominantes

${ }^{2}$ Nos ha interesado principalmente la reflexión desde la perspectiva latinoamericana sobre los controvertidos términos "postmodernismo" o condición "postmoderna". Hay una discusión muy productiva que nos parece menos confusa que partir aplicando mecánicamente aquellos términos. Señalamos algunos siguientes e importantes trabajos desde mediados de los ochenta: José Joaquín Brunner, "Cultura y modernidad en América Latina", Mundo 2 (México, 1987); también del mismo Brunner su "Notas sobre modernidad y lo postmoderno en la cultura latinoamericana", David y Goliath 52 (septiembre 1987) 30-39; Néstor García Canclini, "Antropología versus sociología. ¿Un debate entre tradición y modernidad?", David y Goliath 52 (septiembre 1987) 40-44; Bernardo Subercaseaux, "La apropiación cultural en el pensamiento latinoamericano", Mundo 3 (México, 1987), del mismo autor "El postmodernismo en Chile", Miradas 1 (Chile, 1988); Hugo Achugar, "Postmodernidad y postdictadura: fin de siglo en Uruguay", Cuadernos de Marcha (Montevideo, octubre 1989); George Yúdice, “¿Puede hablarse de postmodernidad en América Latina?”, Revista de crítica literaria latinoamericana 29 (Lima, 1989); Nelly Richard, "Latinoamerica y la postmodernidad", Revista de crítica cultural 3 (Chile, abril 1991); John Beverley, "Izquierda y música popular", Revista de crítica cultural 4 (Chile, noviembre 1991); Celeste Olalquiaga, "Tupinicopolis: la ciudad de los indios retrofuturistas", Revista de crítica cultural 3 (abril 1991); véase los dos números de Texto Crítico (1990 y 1991) dedicados a la "Modernidad y postmodernidad en América Latina". En cuanto a la discusión sobre el postmodernismo, principalmente en Estados Unidos, hemos usado también dos textos básicos para nuestro trabajo: Frederic Jameson, "Postmodernism and Consumer Society", ponencia leída por Jameson primeramente en otoño de 1982 en el Whitney Museum, Nueva York y luego publicada en The Anti-Aesthetic: Essays on Postmodern Culture, Ed. Hal Foster (Seattle: Bay Press, 1983) 111-125. Posteriormente Jameson recorrigió este trabajo para dar una versión más amplia y es la que más se ha divulgado con el título de "Postmodernism or the Cultural Logic of Late Capitalism", publicada en New Left Review 146 (1984). De este hay una traducción al español "El postmodernismo o la lógica cultural de capitalismo tardío", Casa de las Américas 155-156 (marzo-junio 1986) 141-173. También la posición del francés Félix Guattari -que no se contradice con las ideas de Jameson sobre los efectos profundos y complejos de la industria cultural del capitalismo multinacional- véase: "La producción de subjetividad del capitalismo mundial integrado", Revista de crítica cultural 3 (Chile, 1991) 5-10. ${ }^{3}$ Agustín Cueva, “¿Hacia dónde va nuestra socialdemocracia?", 59-67. Nils Castro, "Vialidad de la socialdemocracia. La agenda latinoamericana de hoy y mañana", 51-58. Ambos trabajos en Estudios latinoamericanos 6-7 (México: UNAM, 1989). Véase, James Petras, "Transformaciones globales del socialismo en América Latina," en Casa de las Américas 181 (julio-agosto 1990). 
en muchos novísimos poetas latinoamericanos de los sesentas. Volviéndose a neoexperimentar desde los setenta, principalmente en países con dictaduras militares. ${ }^{4}$ Pero lo realmente importante es que toda esta nueva producción artística latinoamericana habría que considerarla como respuestas estéticas a la condición transnacionalizante de América Latina - principalmente desde la década de los ochenta- como sugiere, por ejemplo, George Yúdice:

Si por postmodernidad entendemos las "respuestas/propuestas estético-ideológicas" locales ante, frente y dentro de la transnacionalización capitalista, ya no sólo en Estados Unidos o Europa sino en todo el mundo, el análisis de las culturas latinoamericanas tiene que partir de esta relación dialógica. ${ }^{5}$

\footnotetext{
${ }^{4}$ Sobre este punto, se ha mostrado ya que muchas formas expresivas no son originales de los setenta u ochenta sino que vienen de las viejas vanguardias. Otra cosa - y más apropiada - es decir que se han reprocesado según los contextos específicos (países, regiones) del continente. Asumir que algunas expresiones en los setenta y ochenta son "fundadoras" no es apropiado. Lo más correcto es aceptar ese reprocesamiento que no supone la imitación "literal" de los originales. Véase para "ruptura", "montaje", "contenido", "imagen de la vanguardia" a Federico Schopf, "Figura de la vanguardia", Revista Chilena de Literatura 33 (abril 1989) 132-138. También a José Emilio Pacheco, "Nota sobre la otra vanguardia," Revista Iberoamericana XLV (enero-junio, 1979). Antonio CornejoPolar, "La problemática del sujeto en la poesía conversacional", trabajo leído en LASA, New Orleans, 1989. También el excelente trabajo de Pedro Lastra, "Poesía hispanoamericana actual" en su Relecturas Hispanoamericanas (Santiago, Chile: Editorial Universitaria, 1986) 129-137. Para el caso específico chileno, Gonzalo Millán en un rastreo "arqueológico" muestra con evidencias innegables que ciertos "experimentalismos artísticos", que aparecieron con mucha fuerza después del golpe militar en Chile (1973), ya venían ocurriendo en la década de los sesenta; véase su "Promociones poéticas emergentes: el Espíritu del Valle", Postdata 4 (Concepción, Chile 1984) 29. También Grínor Rojo, "Veinte años de poesía chilena: algunas reflexiones en torno a la antología de Steven White" en su Crítica del Exilio (Santiago, Chile: Editorial Pehuén, 1989) 72-73.

${ }^{5}$ Yúdice retoma el concepto de Hugo Achugar de "respuestas/propuestas estético-ideológicas" para formular esta definición; ver Achugar, artículo citado, página 106-107. En un reciente artículo de Roberto Fernández Retamar, "Calibán en esta hora de Nuestra América", Simposio Internacional en Sassari, Italia, Casa de las Américas 181 (octubre-diciembre, 1991) 103-117, señala lo apropiado de tal definición de Yúdice así como la convicción de los planteamientos generales de Jameson desde la perspectiva norteamericana. El planteamiento general de Jameson (y que nosotros hemos aprovechado en este trabajo) sobre la cultura postmoderna puede resumirse de la siguiente manera: "Una característica de la cultura postmoderna o del capitalismo tardío (la etapa del capitalismo multinacional y de la etapa de producción con máquinas electrónicas o movidas por energía nuclear a partir de los 40) es la nueva cultura de la imagen o del simulacro a través de la nueva y sofisticada industria cultural (o la tecnología de la producción y reproducción de esta nueva cultura o del simulacro: TV, videos, cámaras de cine, grabadoras, disco-compacto, etc.). En tal cultura la producción estética se ha integrado a la producción general de bienes (es lo que se llamaría lo sublime postmodernista). En la urgencia de producir una nueva línea de productos de apariencia cada vez más novedosa (desde ropa hasta aviones) se produce la conversión de los objetos en mercancía donde la imagen se constituye en la forma final de la cosificación para la transformación de esos objetos en mercancía. Nuestras representaciones defectuosas de una inmensa red de comunicaciones y de computaciones no son más que una figuración distorsionada de algo más profundo, a saber, todo el sistema internacional del capitalismo multinacional de nuestros días".
} 
Si tal propuesta parece adecuada, el siguiente paso sería mostrar (o intentar hacerlo) cómo funcionan estas respuestas en las propias y específicas obras en específicas realidades (países y regiones de nuestro continente).

II

En el poema de Gonzalo Millán "Y tu piel me es doblemente extraña" de su libro Relación personal de 1968 me parece que se inicia un tema inencontrable en los otros poetas chilenos de la promoción de los sesenta:

Mientras en lo alto se iluminan
las ruedas gigantescas y torres
huimos a escondernos
a un cuarto cubierto de postales
de nuestra piel borramos
el olor a perfumes
y el olor a manillas de metal
de nuestras manos
Hasta quedar en la noche
de falsos colores comerciales
desnudos, espantados
sin cuerpos, sin rostros, sin olores.

Lo que es tan significativo de este breve poema en la promoción chilena mencionada y hacia fines de los sesenta es que hay aquí el germen de una nueva forma de percibir poéticamente el espacio urbano chileno asi como la presencia de ciertos y nuevos objetos que comienzan a habitarlo (esos "falsos colores comerciales"). En otras palabras, el espacio urbano aparece registrado como un lugar de consumo que afecta profundamente al hablante y su relación con el otro ("Hasta quedar en la noche/de falsos colores comerciales/ desnudos, espantados/ sin cuerpos, sin rostros, sin olores").

Posterior a su primer libro señalado, Millán escribe a fines del 68 y comienzos del 69 el poema titulado "El automóvil":

Ver "Postmodernism and Consumer Society" $y$ "Postmodernism or the Cultural Logic of Late Capitalism", artículo citado.

${ }^{6}$ Relación Personal (Santiago, Chile: Arancibia Hermanos, 1968). Me he extendido más ampliamente sobre la presencia urbana de este libro en mi ensayo "La visión de la infancia mutilada y su proyección a la mujer y a los espacios sociales en la poesía de Gonzalo Millán" en mi libro La joven poesía chilena en el periodo 1961-1973 (Concepción-Minnesota: LAR, 1987) 39-69. Soledad Bianchi en su artículo "La poesía de G. Millán", Atenea 461 (enero-junio, 1990) 115-132, sin embargo despacha mi trabajo en una sola oración (que en su nota 6, página, 119) de esta manera: "Con frecuencia me parecen discutibles y, en ocasiones, algo mecanicistas [sic], muchas de las interpretaciones que este autor hace sobre la poesía de Millán". Pero lo que asombra (en un trabajo académico) es que Soledad Bianchi no se dé el trabajo - por ninguna parte de su artículo- ni de demostrar ni de discutir eso que ella ve tan "discutible" y "algo mecanicista". 


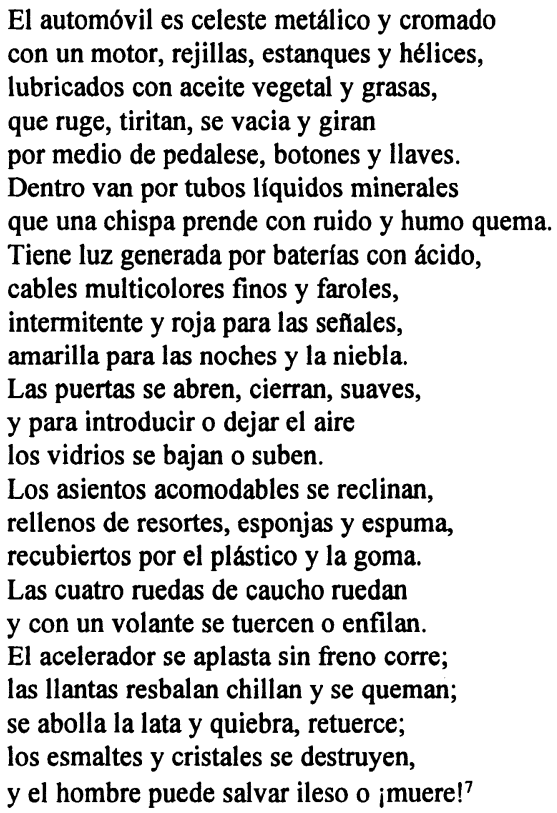

La detallada descripción de esta máquina no sólo es provocada por la perfección de su manufactura interna y externa que a su vez sugiere una relación fetichista con el objeto (una sexualidad-objeto como observaba Jaime Concha en ese entonces). También toda esa belleza tecnológica ejerce una compleja y misteriosa atracción mucho más que el repetido efecto alienante provocado por la máquina o los objetos de consumo. Esta interesante percepción dual de la máquina y objetos de consumo (automóviles, refrigeradores, televisores, etc.) que Millán continuará en su libro Vida (1984). ${ }^{8}$ Sin embargo parece ser

\footnotetext{
${ }^{7}$ Este poema fue leído por primera vez en el otoño de 1969 en la Universidad de Concepción. Jaime Concha refiriéndose a él observó muy agudamente lo siguiente: "Mi primera audición —en un recital de 'La Guarida' [lugar de lecturas poéticas en esa universidad, 1969] y más tarde la primera lectura de "Automóvil" me produjeron justamente esa impresión, la de una sexualidad-objeto (o fetiches)", en su artículo "Mi otra cara, hundida dentro de la tierra (sobre el libro de G. Millán Relación Personal", Atenea 421-422 (1969) 433-434. El poema fue publicado en Nueva poesía joven en Chile, ed. Martín Micharvegas (Buenos Aires: Ediciones Noé, 1972). Finalmente fue incluido en su tercer libro Vida (1984).

${ }^{8}$ Esta percepción dual distingue a Millán de aquella percepción sólo alienante que algunos siempre quieren ver en la máquina u los objetos de consumo. Hay cierta relación de Millán con algunos poemas de Ernesto Cardenal sobre el tema y esa percepción dual (por ejemplo en el poema "Managua 6:30 p.m." de Cardenal: "En la tarde son dulces los neones/y las luces de mercurio, pálidas y bellas .../Y la estrella roja de una torre de radio/en el cielo crepuscular de Managua/es tan bonita como Venus/y un anuncio ESSO es como la luna .../Otro significado/no lo conozco/Las crueldades de esas luces no las defiendo/Y si he de dar un testimonio sobre mi época/es éste: Fue bárbara y
} 
muy distinta a como la vieron en las primeras décadas de este siglo, entre otros, Marinetti, Maiakowski, Huidobro o Diego Rivera. La atracción de los artistas ante la máquina u objetos de consumo masivo y en serie es un fenómeno notorio desde comienzos del siglo para alcanzar niveles sumamente complejos en las sociedades definidas como postindustriales y también en nuestras sociedades periféricas. ${ }^{9}$ La importancia entonces que nosotros vemos en esos dos poemas de Millán ya citados, pero especialmente "El

primitiva/pero poética". Véase nuestra nota 13 más adelante sobre cita de este poema). Pero Cardenal es también bien directo y claro en otros poemas respecto al significado colonialista y transnacional. Perfectamente explicable puesto que denuncia su penetración imperialista en la región centroamericana.

${ }^{9} \mathrm{Al}$ parecer la percepción de la "máquina" u "objetos de consumo" desde las primeras vanguardias artísticas es una percepción compleja y matizada porque no es únicamente un fervor por el objeto en sí ni tampoco es una crítica despiadada a ella porque contribuya a la alienación humana. La percepción en la poesía de Millán sobre el mundo del consumo y la vida de sociedades postmodernas es dual (la larga estadía de este poeta en sociedades postindustriales de verdad, después del golpe militar chileno y exiliado, es fundamental para entender los increibles poemas de "Los nombres de la Era" de Vida (1984). En cambio, la percepción para las primeras vanguardias es distinta. Poe ejemplo, respecto a Huidobro o el "interés por la máquina" en su poesía, lo aclara muy bien Jaime Concha: "Huidobro traslada el futurismo de las cosas artificiales o inventadas por el hombre, al campo de la naturaleza. Es al movimiento del cielo, a la condición migratoria de la población celeste adonde transplanta Huidobro su visión futurista y, por lo tanto, su sensibilidad para lo veloz." (87). Respecto al futurismo propiamente tal, Concha apunta algo muy clave: "El futurismo no es esencialmente la apoteosis del maquinismo: es por lo que despiertan en nosotros de vértigo y dinamismo que las máquinas modernas se hacen estimables para los futuristas. Es ésa, la vivencia de la velocidad, lo primario; lo demás, lo fabril y todo eso, es mera exteriorización" (86). Ver su Vicente Huidobro (Madrid: Ediciones Júcar, 1980). Igual de importante nos parece el siguiente comentario que nos muestra el otro lado de la medalla: la percepción del artista comunista respecto a la máquina en las primeras décadas (donde se puede incluir al poeta ruso Mayakosvski), en la hermosa biografia que escribió Bertram D. Wolfe sobre Diego Rivera, La fabulosa vida de Diego Rivera (México: Ediciones Diana, 1989), 3ra impresión: "Desde hacía mucho tiempo Diego profesaba la convicción de que la pintura debía absorver la máquina si quería hallar estilo de esta época [Wolfe se refiere al año 1932 cuando Rivera viaja a Estados Unidos] ... dominar este maravilloso nuevo material y hacerlo vivir de nuevo en los muros. No se trataba de efectuar una ignorante contemplación desde el exterior, como en el caso de los impresionistas que sólo veían en la industria moderna humo y bruma, atmósfera pluta y fuego de hornos, o una estructura informe a la cual no correspondía ninguna función real. No se trataría del mecanismo estilizado preconizado por Léger, quien reducía toda 'máquina', aun al ser humano, a naturalezas muertas, geométricas, abstractas, ornamentales, sin pasión o fuerza ... tampoco era la máquina retratada como un monstruo devorador ... No, él pintaría el espíritu humano materializado en la máquina, porque ésta es una de las más brillantes realizaciones de la inteligencia del hombre; con la máquina el ser humano domina las fuerzas inhumanas de la Naturaleza, no necesita seguir siendo víctima del hambre, del trabajo aniquilador, desigualdad, tiranía ..."(249). Elie Faure (crítico francés de arte) le escribía a Rivera la siguiente carta el 20 de enero de 1933: "Lo que me dices de América es preferible a lo que ocurre aquí en Francia. La máquina se ha convertido en el enemigo: todos los escritores, pintores y dramaturgos, la hacen objeto de sus anatemas tachándola de burguesa ... los imbéciles aclaman en el Théâtre Français una obra que se declara contra la máquina ... no te imaginas el placer que me causó al ver que utilizaste la máquina como motivo de emoción plástica ... (255-256). 
automóvil", dentro de la promoción poética chilena de los sesentas, es que son los únicos que han hecho una aguda reflexión poética de los efectos del consumo en el proceso de modernización del capitalismo dependiente chileno y que sólo veinte años después el tema volvería a ser retomado como preocupación dominante por cierta parte de la joven poesía chilena post-1973.

Ángel Rama señaló que la naciente transculturación, o la evidencia de una inicial modernidad consumista en muchas urbes latinoamericanas en los sesentas, constituyó una importante influencia en la novísima narrativa de esa década en escritores como Skármeta, Puig, José Agustín, entre otros. Esta transculturación, según Rama, serían "el cine, la televisión, los jeans, las revistas ilustradas, los supermercados, la droga, la liberación sexual, los drugstores, etc."10 Junto con ello — agregará Elena Poniatowska- el rescate del lenguaje lumpen es otro aporte de esa narrativa como lo demuestra la literatura de la "onda" entre 1966-1972 en México. El fenómeno pues de la transculturación ha sido abundantemente demostrado en las ciencias sociales latinoamericanas como consecuencia de los inicios de las transnacionalizaciones que comenzaron a invadir ciertas urbes latinoamericanas con más fuerza en unas que en otras desde fines de los cincuenta y comienzos de los sesenta. En el caso chileno, este proceso con su propia particularidad comenzaría aproximadamente a partir de 1964 con los cambios que hará el gobierno de Eduado Frei. ${ }^{11}$ Modernismo o modernidad desigual — para ser más exactos; consumo para unos pocos; marginalidad acelerada para muchos; es el cuadro más o menos general en casi todo el continente a fines de la década de los sesenta.

Si para Ángel Rama ese nuevo fenómeno de la modernización explicaría el nuevo discurso de ciertos novísimos narradores; por el contrario, la mayoría de los novísimos poetas chilenos de los sesenta no registraron el efecto ni de los objetos de consumo ni de los medios masivos o la industria cultural de aquel entonces con su mercado de mensajes que comenzaba a manipular y modificar a los consumidores. De hecho, resulta imposible encontrar algún libro u otros poemas semejantes a los de Millán arriba señalados en la joven promoción poética chilena de los sesenta. En poetas, por ejemplo, como Quezada, Hahn, Lara, Waldo Rojas, Thito Valenzuela, Cecilia Vicuña, Raúl Zurita, Juan Luis Martínez, etc.; aun cuando adoptaron los recursos que se encontraban en la mayoría de la joven poesía latinoamericana de los sesenta, tales como los recursos conversacionales; el habla coloquial; la incorporación de múltiples voces en el discurso poético; el juego intertextual; cierto montaje y experimentalismo retomados de las viejas vanguardias. En fin, cuando la desacralización del tradicional hablante lírico se convertía en dominante, especialmente para los poetas más experimentalistas (Zurita, Martínez, Valenzuela), sin embargo, y es en esto en lo que quisiera insistir, la modernidad consumista, toda la novedad que en ciertas urbes latinoamericanas provocaba tanto una atracción por consumir esos nuevos objetos así como los posibles efectos de su compleja atracción, según vimos en el

\footnotetext{
${ }^{10}$ Ángel Rama, Novísimos narradores hispanoamericanos en Marcha (México: Marcha Editores, 1981), 23-24.

"Javier Campos, "El contexto socio-histórico de la poesía joven chilena (de los 60)" en La joven poesía chilena en el periódo 1961-1973 (Concepción, Chile: LAR e Institute for the Study of Ideologies and Literatures, 1987) 26-28.
} 
poema "El automóvil" de Millán, es prácticamente in-hallable en la poesía chilena joven de los sesenta. ${ }^{12}$ En cambio, no ocurrió lo mismo para otros novísimos poetas de otras regiones del continente y en otros relativamente jóvenes como Ernesto Cardenal (1925). Poetas, por ejemplo, de El Salvador, Cuba, México, Nicaragua, Panamá, registraron ese fenómeno de transculturación como se confirma al revisar las dos antologías de Jorge Boccanera sobre la novísima poesía latinoamericana de esa década. ${ }^{13}$ ¿Cómo es posible explicar la ausencia de una modernidad consumista en el discurso de la promoción poética chilena señalada?

\section{III}

José Joaquín Brunner, Carlos Catalán y Alicia Barrios son quienes más han analizado los efectos del modelo económico del régimen militar en la cultura y sociedad chilena desde 1973 hasta $1988 .{ }^{14}$ Ellos en ningún momento de su análisis utilizarán los términos

${ }^{12}$ El tema de la modernidad consumista en la poesía chilena no había sido estudiado hasta ahora. Hemos revisado las principales antologías de poesía joven, publicadas principalmente desde 1972 hasta 1991 tanto en Chile como en el extranjero. Ellas suman más de cuarenta. Junto a aquello, está la inmensa cantidad de libros de poesía publicados desde 1961 (nuestro punto de partida para detectar este tema). Resulta largo mencionar todas aquellas referencias en esta nota, sólo remito a los que han sefialado específicamente todas las antologías y libros publicados. Javier Campos, "Arte alternativo y dictadura" en Cuadernos Hispanoamericanos, número especial dedicado a la cultura chilena durante la dictadura, 482-483 (agosto-septiembre 1990) 55-56, nota 2 . También del mismo autor, La joven poesia chilena ... 11-16. Pablo Berchenko, "Elementos para un índice bio-bibliográfico de las últimas promociones de poesía chilena" Ventanal 12 (Francia, 1987) 141-170. Sergio Macías, "Una breve aproximación a 16 años de poesía chilena: 1973-1989" Cuadernos Hispanoamericanos 482-483 (agosto-septiembre 1990) 177-196.

${ }^{13}$ Jorge Boccanera, Poesía rebelde en Latinoamerica (México: Editores Mexicanos Unidos, 1979) y La novísima poesía latinoamericana (México: Editores Mexicanos Unidos, 1980). Es importante señalar que el antecedente poético de la temática del consumo, industria cultural y su mercado de mensajes que promueven las companías transnacionales en América Latina, especificamente en Centroamérica, es el poeta nicaragüense Ernesto Cardenal. Poemas específicos suyos y magnificos, escritos a fines de los cincuenta, comienzos de los sesenta son: "Llamadas"; "Murder, Inc."; "Managua 6:30 p.m."; "Los paraísos más económicos del Caribe ..."; "Oración por Marilyn Monroe". Ver Nueva antología poética de Ernesto Cardenal ( $4^{\mathrm{a}}$ edición) (México: Siglo XXI, 1983).

${ }_{14}$ José Joaquín Brunner et al. Chile: transformaciones culturales y modernidad (Santiago, Chile, FLACSO, 1989). Es un libro importante para entender los efectos de la dictadura en la cultura chilena en los ochenta. Se sintetiza también todo el trabajo de investigación de Brunner en sus múltiples artículos publicados en diversas revistas del continente desde la década del setenta. Véase el artículo de Brunner que resume en pocas páginas aquel fenómeno: "Chile en la encrucijada de su cultura" Cuadernos Hispanoamericanos 482-483 (agosto-septiembre 1990). Respecto a la visión oficialista, Chile con esta modernización iniciada por la dictadura en la última década (los ochenta) “... ha experimentado cambios profundos que están modificando la forma en que las nuevas generaciones de chilenos viven, piensan, estudian, trabajan y descansan. La manera en que se visten, los alimentos que adquieren, la forma en que distribuyen su tiempo libre, las ciudades en las que prefieren vivir, las carreras que quieren estudiar ... estas transformaciones son consecuencia de la política deliberada de integración con el mundo, iniciada en 1975, que echó por tierra las barreras 
ni "post-modernismo" ni menos "condición post-moderna" para referirse a la nueva situación cultural chilena desde el golpe militar, más específicamente a partir de 1980.

Los sociólogos chilenos señalan que cuando la cultura cotidiana comienza, principalmente, a transformarse y a organizarse a partir de la cultura de masas, es decir, en torno al consumo de bienes que promueve una industria cultural (TV, revistas ilustradas, radio, etc.) y su mercado de mensajes, estamos ante uno de los fenómenos más prominentes de la llamada modernidad. Este nuevo fenómeno alcanza su máximo desarrollo dentro de la década de los ochenta y tiene mucho que ver con el proyecto neoliberal del régimen militar. Este proyecto - según los sociólogos mencionados- lo que impone es una modernidad artificial y absolutamente desigual. Para que ello ocurriera el régimen dejó casi toda la economía chilena en manos privadas y altamente integrada al capital extranjero. La conclusión bastante dramática del análisis de Brunner, Catalán y Barrios es que toda la nueva modernidad neoliberal chilena, impuesta autoritariamente y de allí su éxito y rapidez, provocó una profunda fragmentación social así como una acelerada heterogeneidad cultural en la sociedad chilena. Heterogeneidad que en la definición de Brunner es producto del mercado internacional o:

una suerte de postmodernismo regional avant la lettre que, sin embargo, es plenamente constitutivo de nuestra modernidad ... un collage: "Cablevisión. Comics de superhéroes. Infinitud de productos que sacian, inventan y modifican necesidades. Programas de televisión norteamericanos. Tecnologías refinadísimas. Videocasettes. Comunicación por satélites. Videodiscos. Estrategias de consumo cuya implacable logística destruye toda perspectiva artesanal. Películas que han impuesto mundialmente el ritmo, la temática y el punto de vista de la industria norteamericana. Desdén ante la historia de cada nación. Homogenización de los estilos de vida 'deseables'. Control de la revolución informática. Revistas que distribuyen la 'femineidad'."15

Teniendo en cuenta el análisis de Brunner y también la importancia que tuviera antes del golpe militar el llamado Estado de Compromiso, podría deducirse que el impacto de la modernidad consumista chilena de los sesenta era aún débil en las regiones urbanizadas y casi inexistente en las regiones de la provincia para que ella pudiera producir una compleja y dramática fragmentación de la sociedad chilena, especialmente en los sectores más desposeídos asi como una abrumadora heterogeneidad cultural en los términos arriba

del comercio y amplió el horizonte de los chilenos al otorgarles acceso a información, tecnología y bienes de consumos que hasta entonces sólo conocían por sus escasos viajes al exterior ... una nueva revolución está cambiando a este país". Ver Joaquín Lavín, Chile: revolución silenciosa (Santiago, Chile: Ediciones Zig-Zag, 1987) 11-12.

${ }^{15}$ Para el concepto de heterogeneidad cultural de Brunner, véase su Chile: transformaciones ..., 31 42 y 205-211. También su artículo "Notas sobre modernidad ..." 33. Brunner para fundamentar ese concepto cita a Carlos Monsiváis (nuestro collage latinoamericano). Nestor García Canclini en su "Antropología versus sociología ...", 42-44, retoma aquel concepto de heterogeneidad cultural y si bien - dice García Canclini- ella es impuesta por el mercado internacional, no hay que verla siempre como un factor destructivo de elementos tradicionales o populares, sino que es necesario considerar el fenómeno de reapropiación, las interacciones y los entrecruzamientos con culturas populares u urbanas o rurales según específicas regiones del continente. 
señalados. Es quizás eso lo que explique que aquella transculturación no hubiera sido una preocupación dominante en la poesía joven chilena de los sesenta con la rara excepción de cierta poesía de Gonzalo Millán. ${ }^{16}$

También, resulta muy curioso que los novísimos poetas, los más experimentalistas de los sesenta como Raúl Zurita, Juan Luis Martínez, entre otros, que en el período del régimen militar serían parte de los llamados "neovanguardistas", los de regiones más urbanas, no hayan incorporado ni la naciente modernidad consumista chilena de fines de los sesenta ni menos la abrumadora modernidad neoliberal a partir de los ochenta. Y no la incorporaron no porque no les haya interesado sino porque no la vieron como un fenómeno que pudiera estar afectando profundamente a la sociedad chilena hacia 1981. Tal despreocupación no disminuye de ningún modo el valor de poetas como Raúl Zurita, Juan Luis Martínez, Diego Maqueira, entre otros. La tendencia denominada "neovanguardista" (en la cual se incluyen esos tres poetas anteriores), así como otras tendencias post-1973, fueron la de testimoniar dos cosas bien precisas: quiénes realmente estaban provocando autoritariamente ese fenómeno de fragmentación señalado por Brunner; y quiénes estaban recibiendo a su vez sus efectos. Para que así fuera, como hemos señalado previamente, re-trabajaron muy conscientemente, en especial la tendencia "neovanguardista", tanto los recursos formales que había legado la vanguardia de los veinte y los treinta así como la re-aparición renovada de muchos de esos recursos que existían también entre la mayoría de los novísimos poetas latinoamericanos de los sesenta, pero adaptándolos ahora al contexto de la dictadura. Enrique Lihn, refiriéndose con mucha claridad a esta neovanguardia post-1973 en Chile, ha dicho: "El neovanguardismo desgramaticaliza para apoyar en la impertinencia sintáctica, sus efectos de transgresión de lo real y de lo imaginario, postulando un cierto absolutismo del lenguaje como productor, en sí mismo, de referentes. ${ }^{17}$

Sin embargo siempre hay excepciones importantes respecto a la plasmación de aquella naciente modernidad consumista durante la dictadura ya señalada. Y me refiero a excepciones en la producción poética solamente puesto que el género más adelantado a esto fue el teatro, cuya preocupación por los efectos de aquel fenómeno y sus consecuencias

${ }^{16}$ Digo excepción al revisar dos importantes antologías de comienzos de los setenta, la de Martín Micharvegas, Nueva poesía joven en Chile (Buenos Aires: Ediciones Noé, 1972) y la de Jaime Quezada, Poesía joven de Chile (México: Siglo XXI,1973). En la primera antología predominan más los poetas rupturistas (Juan Luís Martínez, Raúl Zurita, Thito Valenzuela). Millán publica aquí los poemas "Refrigerador" y "Automóvil" resultando ser los únicos poemas que tratan sobre esa temática. En la antología de Quezada no se incluye a ninguno de los poetas más vanguardistas que incluía Micharvegas. Millán es incluido en la antología de Quezada, pero el tema no es tratado en los restantes poetas que allí aparecen antologados (O. Lara, H. Lavín Cerda, H. Miranda, F. Pérez, J. Quezada, F. Schopf, M. Silva y O. Welden).

${ }^{17}$ Enrique Lihn en "Preprólogo" a 16 poetas chilenos (antología) ed. Erwin Diaz (Santiago, Chile: $\mathrm{SECH}, 1987), 10$. Respecto a nuestro juicio de que "no la vieron [la modernidad consumista] como un fenómeno ...", el crítico y profesor norteamericano Nick Hill me facilitó una entrevista (grabada) que en 1981 él hizo a Raúl Zurita en Santiago. En ella el profesor Hill le pregunta si todo ese auge consumista que él (Hill) observa en la capital junto a una nueva tecnología que comienza a notarse es una preocupación poética para él. Zurita responde que no cree que aquello sea un problema que a él mismo le importe en ese momento (incluyendo a los otros poetas neovanguardistas) sino la represión de la dictadura. 
sociales de esas "modernizaciones" comienza con fuerza ya en 1980. Una excepción, y en orden cronólogico, es el poeta Rodrigo Lira (1949-1981), quien en 1979 gana el primer premio de poesía de la revista La bicicleta. La otra es el libro de Carmen Berenguer, Huellas de siglo (1986). ${ }^{18}$ Interesa citar parte de ese poema de Rodrigo Lira (los subrayados son nuestros, la palabras en paréntesis del autor):

" 4 tres cientos sesenta y cincos

$y$ un 366 de onces"

No podrás: alguien sujetará a usted del brazo justo a tiempo

alguien o algo, algún robot por ejemplo

y alguien —o (algo) - llamará a una ambulancia

a través de un citófono a un teléfono que llamará a una central que

pasará el mensaje a otro teléfono etcétera

todo a velocidad escasamente menor que la de la luz o la de tu cuerpo en la frustrada caída

probablemente el radio del radiopatrulla no será necesario

habrá una sirena o tal vez no, habrá en todo caso un silencio eléctrico

de terapia de choque tac/

un vacío

$y$ un hueco para ti en una terapia

de grupo

de un grupo cualquiera

y sean cuales fueren los cuentos que te cuenten, desgraciado

la cuenta que te pasen

saldrás del hospital clínica o centro médico

\footnotetext{
${ }^{18}$ Respecto a lo que hizo el teatro desde los ochentas sobre este tema, véase a María de la Luz Hurtado, "Teatro chileno bajo el autoritarismo: 1973-1980" en Teatro chileno de la crisis institucional (antología crítica), editores Hernán Vidal, et al. (Minneapolis: University of Minnesota y CENECA, 1982) 45-49. Rodrigo Lira gana ese concurso con este poema. Fue publicado en La bicicleta 6 (marzo-abril 1980) junto a otros dos ganadores que estaban en el exilio (a O.Lara el segundo premio; a C. Bertoni el tercer premio). Este poema que me parece muy importante en la poesía post-1973 no se ha incluido en ninguna antología de la poesía chilena aun cuando el jurado fue integrado por Enrique Lihn, - quien escribió un lúcido comentario en ese mismo número citado de La bicicletaLuís Sanchez Latorre, R. Zurita y M. Silva. También compárese el poema de Lira con el de C. Riedemann (que incluimos en páginas posteriores), especialmente las referencias e incorporación de la tecnología de las comunicaciones: "teléfonos", "citófonos", "robot", "pinpong electrónico" (no aún los "video games") en Lira; "minicomputador", "fotocopiadoras", etc., en Riedemann. Hay once años de diferencia entre esos dos poemas, pero muestra perfectamente el proceso de "modernización" entre esos años. Seis años después del poema de Lira el mercado de mensajes será más complejo y abrumador, como mostraremos más adelante al referirnos a los poetas A. Figueroa y E. Mardones. Carmen Berenger publica en 1986 su Huellas de siglo y en la sección titulada "Santiago Punk" se puede encontrar el tema del consumismo en el espacio de la dictadura militar (de los primeros años de los ochentas). Es muy significativo que el epígrafe con que Berenguer abre esa sección sean unos versos de Millán del libro Vida (1984), especialmente de la sección que refiere a los objetos de consumo y al mundo postindustrial: "Los maniquíes lucen saludables/Son felices./Están siempre sonriendo".
} 


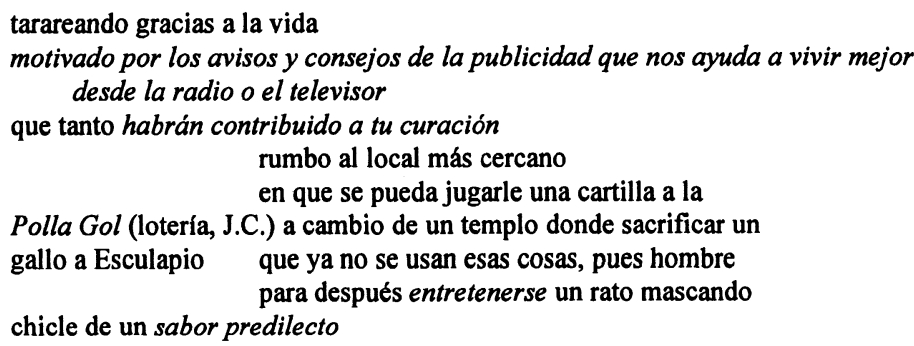
en la máquina de (pinbol) o pinpón electrónico ...

El título del poema hay que descifrarlo. Es un título en clave. Hace referencia a los 5 ó 6 años de la dictadura: desde 1973 a 1979, indicando por esta última fecha el momento y las condiciones contextuales en que se ha escrito el poema. El título nos indica que todo el texto que sigue constituye el espacio social del país, vivido hasta entonces bajo la dictadura. En aquel espacio los seres viven en una condición de ocultamiento y vivencias enajenadas. Descifrar esos signos emitidos por ciertos medios tecnólogicos o/y masivo (la industria cultural y los inicios del consumo que en los ochenta vendrían a convertirse en agentes mucho más poderosos) es comprender su misterioso control, manipulación y adormecimiento de los individuos, transformándolos, manipulándolos, sin ellos darse cuenta, en sujetos estancados e impotentes para cualquier acción.

Este poema de Lira con todo su significado que tenía para ese entonces, pero incorporando críticamente hacia 1978 una industria cultural y su mercado de mensajes no tan sofisticado y abrumador como lo será hacia mediados de los 80 bajo la dictadura, es una excepción bastante significativa en la primera etapa de la poesía post-1973.

Pero aun así, creemos que la preocupación por el impacto complejo de la modernidad consumista neoliberal de los ochenta como proyecto poético mayor y no meramente en poemas o versos aislados, entre los novísimos poetas post-1973, no va a comenzar ni por los poetas neovanguardistas ni por los poetas propiamente de la capital ni menos por aquellos poetas de los sesenta que permanecieron en el país después del golpe militar, sino que parece comenzar por los jóvenes poetas de la provincia o del lejano sur quienes hacia 1985 no alcanzan los treinta años de edad. Es decir, registrar y problematizar una de las invasiones más profundas de la modernidad consumista neoliberal en los aún visibles modos de vida pre- o semi-modernos de las regiones de la provincia o del lejano sur. ${ }^{19}$

${ }^{19}$ En relación a este juicio y propuesta nuestra es necesario hacer conexión con la llamada "poesía lárica chilena". La recuperación de una época de arraigo ha sido casi uno de los lugares comunes en este tipo de poesía. Son dominantes los temas como la ídilica infancia perdida; el paisaje ameno de regiones en estado casi natural (no contaminadas por la modernidad, la tecnología); la recuperación de la fraternal comunidad familiar; el trabajo artesanal; la tradicón oral, etc. Jaime Quezada, importante poeta de esta línea lárica, en 1968 sintetizaba muy bien el enemigo de lo lárico: "Una nave espacial mancharía el color de mi cielo (mi infancia rodeada de calles de cerezos, de caballos ...)", Trilce 13 (1968) 59. En 1986 otro poeta de la tendencia lárica, Floridor Pérez, publica Chilenos y chilenas, poesía donde se reacciona ante la entrada al espacio lárico del consumismo, industria cultural, medios masivos, avances tecnológicos, privilegiando la condición rural-lárica. Un libro 
En el año 1986, casi veinte años después de los dos poemas de Millán que hemos señalado, Alexis Figueroa (1956), poeta de la provincia chilena, publica su primer libro cuya poesía no tiene mucho parecido temático a la abundante escrita en el país, aunque la organización de su discurso, especialmente el polifónico montaje, es ya una práctica dominante en otros poetas (Martínez y Maqueira principalmente). Ese mismo año obtiene el primer premio Casa de las Américas con Virgenes del Sol: Inn Cabaret. El subtítulo bilingüe del libro - "Vienbenidos [sic] a la máquina/Welcome to the T.V."- nos señala de inmediato que todo el polifónico discurso poético saldrá desde la misma pantalla de televisión:

... desde la pantalla cascadas de indios sioux caen sobre el suelo/el general Patton ruega que tiendan su caballo/emperadores Ming compran Coca-Cola a los occidentales en las riberas del Yang-Zze/un cliente reclama por qué en el vino emerge un submarino/un garzón tropieza con las ruinas de Hiroshima/alguien se escapa sin pagar por una puerta abierta en la T.V./en plena vista baja una nave con marcianos, un mozo les enfrenta con spray insecticida/un mono coloca a Bach en el estereo/ ... una muchacha que sirve a pecho descubierto se abre suavemente un seno y después saca un completo/de pronto cantan All you need is love/ ... bajo algunas mesas soldados S.S. torturan a gente a punta de soplete/María Madonna y sus girlfriends descienden desde el cielo/ ... camareras venden profilácticos con estampas de los Incas/... una cocinera se muele las dos piernas y después prepara sanduichs de pate ... ${ }^{20}$

No estamos ahora ante el minucioso y distanciado objetivismo de los objetos de consumo como era el caso de aquella poesía observada en Millán en 1969, sino frente a la fusión del hablante con la máquina productora de múltiples imágenes visuales. Si seguimos la terminología de Brunner, podemos decir que el hablante en esta poesía - y es aquí donde radica la novedad poética - se ha fusionado absolutamente con la complejidad del mercado de mensajes o con el productor de subjetividad masiva. El libro total de Figueroa

que se aferra a esa fraternidad comunal. Un aviso profundo de que probablemente vamos a perder algo irrecuperable con esa modernidad neoliberal (¿la pérdida de la cultura popular, los elementos tradicionales de que habla García Canclini?). Esta pérdida está dramáticamente conectada con la destrucción ecológica de esos espacios por el avance modernista-transnacional. Véase por ejemplo el video de Pablo Lavín "Del chip al microship" (1991), documental sobre los efectos ecológicos que está produciendo la explotación de materias primas por las multinacionales japonesas en el sur de Chile. Para grupos multinacionales en Chile, véase a Patricio Rozas et al., nota 1 . Creo entonces que los novísimos, los del lejano sur, donde aún prevalece una cierta condición lárica, también se dan cuenta de ello, pero no creo que rechacen aquella modernidad como planteamos en las páginas siguientes. Finalmente, Jameson en "Postmodernism or the Cultural Logic ...", es mucho más enfático al respecto: "... el 'camino campestre' de Heidegger ha sido irremediablemente e irrevocablemente destruido por el capitalismo multinacional, por la revolución verde, por el neocolonialismo y la megalópolis, que construyen sus supercarreteras sobre antiguos campos y solares y convierte la 'casa del ser' de Heidegger en condominios o en edificios paupérrimos, infestados de ratas y carentes de calefacción" (traducción nuestra).

${ }^{20}$ Virgenes del sol: Inn Cabaret (Concepción, Chile: Cuadernos Sur, 1986) 62. 
está configurado como una complejísima simultaneidad de discursos, espacios, tiempos, personajes reales o/e imaginarios. En fin, un discurso con variadas voces cuyo montaje no es nada nuevo puesto que se origina en las viejas vanguardias de principio de siglo. Este hablante, inimaginable en los poetas chilenos de los sesentas, se ha disuelto en una compleja variedad de voces que provienen principalmente de esa industria cultural, insertada ahora con mucho más fuerza que nunca en los espacios-grupos marginales y profundamente fragmentados de la realidad sudamericana. Voces de los videos clips transnacionales, de las telenovelas latinoamericanas; publicidad de revistas; voces tomadas del cine mezcladas con letras de boleros, tangos o rock; voces de personajes históricos o ficticios de la literatura; voces coloquiales, irreverentes; voces de grupos marginados de la cultura popular urbana y/o rural. Lo que hay aquí en definitiva es un artefacto o pastiche visual sudamericano, aparentemente similar al pastiche post-moderno de las sociedades post-industriales del llamado capitalismo tardío (ya volveremos a esto en nuestra conclusión final).

Se puede observar muy bien que en el libro señalado de Alexis Figueroa hay una notoria influencia de la industria del video transnacional y del video alternativo chileno, especialmente de ciertos videos de 1988. También una cierta similitud con el impactante film del colombiano Victor Gaviría, Rodrigo D (sin futuro), situado en Medellín en 1988, en cuanto al reprocesamiento de lo transnacional insertándose con la cultura popular-marginal (la música y letra del grupo "Sex Pistols" con la droga, el tango, elementos vivos de cultura rural insertada en la periferia-marginal de aquella ciudad latinoamericana, etc.). Si bien este film es posterior al libro de Figueroa, sin embargo existe una impresionante relación entre ambos por contener el mismo fenómeno de influencia transnacional pero reprocesado en nuestras periferias según la particularidad de cada país y región. ${ }^{21}$

\footnotetext{
${ }^{21}$ J. Carlos Altamirano, en "The Audio-Visual Battle of Chile", artículo incluido en el folleto titulado Internal Exile (New Film and Videos From Chile), Premiere at The Museum of Modern Arte, mayo 4-7, 1990, Nueva York, dice: "La gran demanda y producción de publicidad se acelera en los comienzos de los 80 a causa de muchas compañías multinacionales de publicidad que se abren en Santiago ... El vacío que dejó la falta de producción fílmica fue suplantada desde esos comienzos de la década [1980] por la enorme expansión del mercado de videos. Un total de 200 mil máquinas de videos y 30 mil cámaras de videos hay ahora en Chile [1990]. Sobre 400 mil cassettes vírgenes se consumen anualmente por el mercado de videos local y 45 mil son importados para uso profesional. Estos números pueden ser actualmente bajos puesto que más cassettes pueden ser importados directamente por instituciones que gozan de privilegios especiales. Esta importación masiva de videos y equipos ha permitido a muchos artistas, grupos de cine e instituciones educacionales usar el video como un medio alternativo de comunicación frente a la televisión y a los medios masivos controlados por el estado" (la traducción es nuestra), 21. Hay ciertos videos alternativos importantes que se enfrentan a esa transnacionalización (y se enfrentaron a la dictadura) usando formas formas experimentales, novedad de la imagen, etc. Son, por ejemplo, los de: Juan Carlos Bustamante, "Historia de lagartos" (1988) (crítica a las modernizaciones del régimen); Francisco Arévalo, "Cargadores de fantasía" (1988) (crítica a la manipulación de los medios masivos); Leopoldo Correa, "Tres mujeres" (1988) y Juan Downey, "NO" (1988) (uso del video-música con fondo político); Néstor Olhagaray, "Historia de una entrevista" (1988) y "La cita" (1988), hecho con Marcela Poch (combinan y contrastan formas de los medios de comunicación de masas y sus funciones sociales. Se mezclan -en "La cita"- el sonido de telenovelas y disparos a sangre fría de anónimos seres humanos en un magnífico uso de la cámara). La influencia pues del video se ve claramente en la poesía novísima de A. Figueroa y de E. Mardones quienes han crecido en la cultura transnacional de los ochenta.
} 
Menos apocalíptica que la poesía de Figueroa me parece la invasión moderna neoliberal en otro poeta del lejano sur, Clemente Riedemann (1953):

"Te miran el culo desde arriba"

Cuídate, Rodríguez

que te pueden insertar micrófonos

del tamaño de una lenteja en las murallas, en tu máquina de escribir, teléfonos

citófonos, en tus propios slips

camarada.

(Dispositivos colocados en máquinas de escribir eléctricas transmiten las señales emitidas por las teclas a un equipo decodificador ubicado fuera de tu casa ((como quien dice "in-put $\&$ out-put" al servicio de las fuerzas del mal)) Cachai?)

En serio, Rodríguez

sin ánimo de bromear, los mensajes

de tu minicomputador pueden ser leídos

por unos ojitos como de mina copuchenta ocultos

en su interior, o por sistemas de intercepción estacionados $a+d e 1 \mathrm{~km}$. del lugar, los que recogen sus ondas radiales sin hacerse el menor problema (es que se trata de equipos buena onda, loco)

Te pueden emitir rayos láser focalizándolos en las VENTANAS para leerte las palabras a partir de las vibraciones que tu voz ocasiona en los cristales. Micro-ondas dirigidas a las paredes pueden capturar reverberaciones de casi todo lo que está sucediendo adentro, para que una computadora (no la tuya) las analice.

Ojo con las fotocopiadoras: cámaras -que miran como la Anouk Aimee en "La Cortina Carmesi"- instaladas dentro de ellas pueden fotografiarte documentos que ingresan suave silenciosamente a esas máquinas maravillosas ...

También, Rodríguez

-me duele decírtelo - satélites espías te televisan el culo mientras fornicas, efectúan acercamientos con sus zooms para hacerte arte rupturista de retaguardia 
con tus lunares, tus espinillas y tus

cicatrices desde el espacio. ${ }^{22}$

A Riedemann le interesa registrar esa invasión de la moderna tecnología como una rara e interesante maravilla que invade ciertos espacios nuestros, antes incontaminados por esta alta tecnología y consumo bien sofisticado. Toda aquella invasión el hablante la ve como un procesamiento positivo tanto en el nivel de lo cotidiano como en el nivel de la imaginación, además de re-valorizar a su manera lo sustancial de la poesía lárica. "Poéticamente me interesa - me decía en una entrevista personal- juntar la carreta y el computador". Creo además que esta nueva poesía de Riedemann al recuperar el humor (casi perdido en la poesía post-golpe y en la del exilio) se sobrepone a cierta condición marginal y profundamente pesimista de alguna novísima poesía de la capital. Esto nos parece importante porque implicaría otro paso en la novísima poesía chilena de este fin de siglo, es decir superar la poesía de marcado carácter testimonial que cubrió toda una década (1973-1985 aproximadamente). Carmen Foxley, por ejemplo, en 1987 refiriéndose a la obra de un muy novísimo poeta de la capital (Santiago) parece resumir la preocupación dominante de esos jóvenes poetas, los que en 1973 (golpe militar) tenían apenas diez u once años. Dice Foxley:

Este hablante descubre una ciudad fantasmagórica en la que transitan sujetos sin energía, apáticos ... los espacios urbanos en esta poesía son barrios abandonados donde la juventud deambula desocupada y ajena, con ánimo depresivo, sin energía, sin destino y sin lugar ... caminando acorralados por las calles, el barrio, la ciudad, etc. ${ }^{23}$

Sin embargo, creemos que es Enrique Lihn quien con Paseo Ahumada (1984) ya había poéticamente plasmado aquella dramática caída en la más profunda miseria de los sectores marginales junto a su ya definitiva orfandad. Paseo ... es el espacio simbólico de todo el país hacia comienzos de los ochenta: un espacio esperpéntico. La mayoría de los personajes de este libro son mendigos. Son vendedores ambulantes de objetos de consumo importado, seres desamparados, huérfanos-marginales. En oposición, hay también un sector minoritario, despreocupado y represivo que goza de bienes y poder paseándose por esa calle de nombre Ahumada de Santiago, convertida durante el régimen - a imitación europea o de grandes metrópolis- en un exclusivo recinto de paseantes. ${ }^{24}$

${ }^{22}$ Primer arqueo (Valdivia, Chile: Editorial El Kultrun, 1990), 17-18. Como señalamos en nuestra nota 18, es interesante relacionarlo con el poema de Rodrigo Lira.

${ }^{23}$ Carmen Foxley, en "Prólogo" a La comarca de los senos caídos (1987) de Victor Hugo Díaz. Esta orfandad o marginalidad está socialmente explicada por J. J. Brunner: "Como muestran consistentemente los más serios estudios realizados durante esos años, ocurren simultáneamente con la preservación de la pobreza masiva, con el ciclo de alto desempleo que llegó a durar cerca de una década y con extendidos fenómenos de armonía entre los jóvenes de los sectores marginalurbanos" en "Chile en la encrucijada de su cultura" Cuadernos Hispanoamericanos 482-483 (agostoseptiembre) 25.

${ }^{24}$ Creemos que el importante libro de Diego Maquieira (1953), La Tirana (1983), junto al de Lihn (Paseo Ahumada de 1984), también corresponde y sería otro ejemplo notable de la atmósfera premodernizaciones del régimen militar en la poesía post-1973. El poeta Tomás Harris en reseña sobre 
De evidente naturaleza Pop-Art es ya la poesía de Egor Mardones (1954). La obra de este joven poeta se construye reprocesando algunos materiales de la cultura de masas, principalmente los comics o cartoons de revistas y periódicos, pero sin llegar al uso diverso de otros materiales en serie de naturaleza masiva-consumista como lo hicieron primeramente los iniciadores del Pop-Art (avisos comerciales, marcas de bebidas, fotografías de productos de consumo masivo, avisos de comida tomados de los periódicos, etc.). Aquí un fragmento de su libro Miramar Hotel (1985-1987):

A esta hora estarán subiendo las escaleras al cielo azul miramar hotel enfundados en esos góticos abrigos nueva ola con nadie sabe bien qué músicas kitsch en la banda sonora que ellos no escuchan ni escucharán jamás estarán quitándose las máscaras que les cubren en cuerpo ciudad ano la camisa de fuerzas armadas/la pálida que llevan siempre consigo adonde vayan

contemplando desnudos y esplendentes las arenas el mar o AL OTRO LADO el Gran Muro de la fábrica abandonada con esa imagen del mural que sus ojos documentalmente se niegan a dejar de registrar como una marca a pesar de los pesares de innumerables capas de cal y de LOS MALOS AÑOS PARA EL AMOR Y EL OLVIDO

agora

soñando despiertos amándose hic et nunc a como los pervierta su IMAGINAZIÓN BRIAN DE PALMA sin siquiera nombrarse y así por todo

La Tirana señaló: "Este libro es la irrupción de lo erótico-marginal de la extrema miseria y producto del desmoronamiento que deja libertad para los impulsos animales. El texto es una fiesta sincrética donde ahora ella (la Tirana) es una puta religiosa. Como sacerdotiza desmoronada y lúmperica [lumpen] se desplaza por distintos escenarios urbanos: los marginales y los de poder [el Palacio de Gobierno, los centros culturales de las clases dominantes, etc.] en "D. Maquieira, La Tirana", El Espiritu del Valle 1 (1985), 82-83. Si bien La Tirana es un texto polifónico (incorpora varios discursos o hablantes), intertextual, desacralizante, un discurso donde se privilegia una voz desde los márgenes, no deja de ser un texto testimonial de un período del régimen ya señalado. Sin embargo no se incorpora la cultura de la imagen de la industria cultural y su mercado multinacional de mensajes (característica principal de la expresión cultural postmoderna en términos de Jameson). El libro posterior de Maquieira, Los Sea-Harrier en el firmamento de eclipse (1984-1985), se repiten pero con mucho más complejidad las múltiples referencias culturales intertextuales y voces (la de la alta cultura o del canon y la cultura-lenguaje-marginal). De igual manera se puede incluir en este grupo a Gonzalo Muñoz con su libro Exit (1981). Este libro está estructurado a la manera de un guión filmico pero donde está muy claro allí el ambiente lumpen-marginal de sus personajes y ambientes. Finalmente nos preguntamos ¿cómo se ha estudiado esta producción? ¿qué aproximación? En un Congreso Sobre Literatura en Chile, 1984 (donde hubo allí trabajos sobre Maquieira, Zurita, manifiestos, testimonios del propio Zurita, Diamela Eltit, G. Muñoz, entre otros), la discusión teórica o el vocabulario más usado fueron: "exilio, poesía; narrativa, vanguardia, escena, marginación, estructura, historia, lectura, discurso, texto, palabra, oralidad, enunciación, significación, significante ...", Manuel Jofré, "Un coloquio sobre literatura en Chile" en Araucaria 29 (1984) 114. Como se puede ver, en ningún momento se usaron los términos "postmoderno" o "postmodernidad", etc., lo que nos demuestra que tal terminología para enfrentarse a la producción artística chilena sólo comienza a ser usada en Chile sólo hacia 1987. 
el reloj, idos, hasta que se los devoren el alcohol y las drogas y el amorbretón y la llameante madrugada que hace bastante amenaza con llevarse todo cuanto por aquí todavía parece (parece)

VALER LA PENA

(Inmediatamente después del poema, Mardones incluye un comic recortado de una fotonovela mostrando a dos amantes. También incluye otros recortes tomados de periódicos de la sección de "consultas de los lectores" donde éstos piden información sobre anfetaminas y otras drogas. J.C. $)^{25}$

Al igual que el hablante de Figueroa, el de Mardones también se fusiona con los medios masivos de producción de mensajes puesto que la historia poética de su Miramar Hotel es el proceso mismo de la filmación de esa historia, determinando así un hablante múltiple (camarógrafo y voyeurista junto a los hablantes de los comics y avisos de periódicos y referencias intertextuales). Esta poesía es otra novedad dentro de la nueva poesía chilena de los 80 por lo siguiente: es un redescubrimiento tardío del Pop-Art en las regiones del lejano sur sudamericano o la vigencia reprocesada $-y$ de allí su originalidad- 25 años después de lo que Andy Warhol y Roy Lichtenstein desarrollaron en Estados Unidos en la década de los sesenta (para Jameson el Pop-Art es una de las primeras expresiones culturales post-modernas en Estados Unidos). Y hay que decir que nunca hubo una influencia dominante del Pop-art en la poesía chilena con la excepción otra vez de Gonzalo Millán en su poema "Refrigerador" (1972), producto tan preferido del Pop-Art:

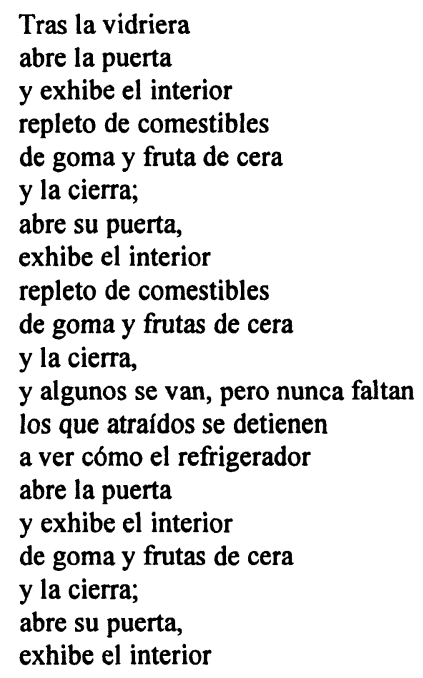

\footnotetext{
${ }^{25}$ Miramar Hotel (1985-1987) de Egor Mardones (1954) permanece aún inédito, pero es un texto importante en la novísima poesía chilena que alguna vez tendrá que publicarse. Federico Schopf es el único quien ha comentado este inédito.
} 
repleto de comestibles

de goma y frutas de cera

y la cierra $\ldots{ }^{26}$

Este poema es el único ejemplo encontrable en la poesía chilena de los sesenta donde hay la influencia del Pop-Art o su relación con él por casual coincidencia. Es claro que en Millán persiste aquella percepción dual que hemos señalado anteriormente respecto a la producción en serie de objetos de consumo masivo, es decir: objetivismo fetichista y asombro. Postura mucho más crítica que no fue la preocupación de Marcel Duchamp y menos la línea Pop-Art norteamericana de Andy Warhol o Roy Lichtenstein, probablemente por ser Millán un poeta de la periferia y no uno de la metrópolis post-moderna donde aquellos objetos de consumo se ven con distintos ojos y otra afectación. Aquellos artistas estadounidenses lo que hacen es incorporar los objetos de consumo y del mercado de mensajes de infinidad de productos a la categoría artística. Para Jameson, el arte de Warhol (y el Pop-Art en su totalidad) no es contestatario a la sociedad de consumo, por el contrario, lo que hace es nada más que revitalizar el mercado consumista de las sociedades postindustriales. ${ }^{27}$

V

Queremos terminar este trabajo con tres conclusiones respecto a la poesía chilena de este fin de siglo que me parece pueden extenderse también —con sus especificaciones según la región o el país del que se trate- al resto de América Latina. La primera es que el desarrollo de la industria electrónica y la revolución digital de los 70-80 han producido una gran sofisticación en la imagen visual-auditiva de los a su vez sofisticados medios masivos o industria cultural para su mercado de mensajes consumista y manipulación imaginativa o producción de subjetividad sin límite, no comparable a la otra transculturación - término que entonces empleaba Ángel Rama - de los años sesenta en América Latina. Toda esta objetiva y abrumadora invasión de la industria cultural al servicio del consumo

(26) "Refrigerador" fue publicado en Nueva poesía joven en Chile, ed. Martín Micharvegas (Buenos Aires: Ediciones Noé, 1972) 52. Luego se incluye en su libro Vida (1984), en la subsección "Refrigerador" de la sección "Nombres de la Era".

(27) El Pop-Art se inicia en los comienzos de los años 60 en Estados Unidos, Inglaterra y Europa del Oeste. No fue un movimiento en el estricto sentido del término. Los artistas no formaron grupos ni publicaron manifiestos. El Pop-Art usa imágenes existentes de la cultura de masas ya procesada (aun cuando existen antecedentes desde los impresionistas en la incorporación en sus telas de objetos de consumo masivo, pero en un segundo plano). Es decir, toman prestado de la publicidad, fotografia, tiras cómicas y otros recursos masivos, producidos en serie. Se reconoce a Marcel Duchamp como la mayor influencia y contribución al Pop-Art, especialmente por sus ready-mades (los objetos funcionales producidos en forma masiva), sacados de su contexto (sin ninguna mediación fisica) y presentados como obra de arte. Lo importante para todo Pop-Art es que la imagen favorita de estos artistas se concentra con más fuerza en los objetos producidos masivamente que en la figura humana y que en el paisaje rural o ciudadano los cuales aparecen raramente y a veces de manera sintética. Véase el estudio y texto ilustrado de Marco Livingstone, Pop-Art: A Continuing History (New York: Harry Abrams, Inc, 1990) 9-13. 
masivo que a su vez sigue continuando su veloz carrera de sofisticación sin término, no cabe duda que debe alterar de algún modo una previa imaginación; transformándola, aniquilándola o desarrollando otras. De aquella transculturación de los sesenta, la narrativa de Manuel Puig puede ser un ejemplo bien clásico de la recodificación de la cultura masiva por la entonces más dominante industria cultural (el cine norteamericano de los treinta y de los cuarenta preferentemente). De tal manera, si la modernidad neoliberal chilena (y otras del resto del continente) dado ese proceso extremo y nuevo de transnacionalización de nuestra ya conocida condición de dependencia, está reproduciendo e importando como nunca antes lo que hacen con aquella sofisticación visual-auditiva las sociedades de verdadera condición post-moderna, los efectos serán insospechados en nuestras regiones latinoamericanas con características semi-modernas de existencia o donde desde hace décadas la verdadera modernidad (salud, alimentación, vivienda, educación, recreación) para amplios sectores sociales aun no ha pasado ni pasará quizás nunca a visitarlos. ${ }^{28}$

La segunda conclusión es que toda la poesía chilena post-1973 (1973-1991) está dentro de dos periódos importantes del régimen. El primer periódo es una etapa de acelerada fragmentación social y absoluta orfandad de vastos sectores de la sociedad chilena provocadas tanto por la represión como por la institucionalización autoritaria de la dictadura. La otra etapa es a partir de la aplicación intensa del modelo neoliberal y el Plan de Modernizaciones (1980). En la etapa primera se ha dicho ya que el carácter testimonial es recurrente en casi toda la poesía a través de variadas tendencias y renovadas formas de poetizar. Si bien -agregamos nosotros-ciertas formas no son absolutamente nuevas ya que algunas provienen de las viejas vanguardias o de formas que ya los novísimos de los sesenta venían practicando, sin embargo se re-adaptan, se neo-experimentan en relación a la condición de vida bajo la dictadura. En la segunda etapa, desde 1980, aparece con fuerza en la sociedad chilena una modernización consumista y profunda invasión de la industria cultural (uno de los fenómenos más prominentes de la modernidad, en términos de Brunner). La novísima poesía comenzará a registrar esta última etapa solamente a partir de 1984 aproximadamente (el teatro ya lo haría desde 1980; el video alternativo desde 1984, alcanzando su mejor expresión en 1988; y el cine joven chileno desde 1985). Lo interesante que observamos en esta segunda etapa es que sean los jóvenes del lejano sur o de la provincia a quienes les interese problematizar de manera muy particular esa modernidad consumista neoliberal en sus textos poéticos, puesto que nunca como antes ni como en los sesenta aparece invandiendo y comenzando a alterar modos de vida semimodernos. Es decir, la real invasión de la modernidad neoliberal en el interior del país sería de otra complejidad a como ocurre en los centros más urbanizados y más estrechamente conectados por décadas al fenómeno de transnacionalización. Y probablemente sea también uno de los factores que ha contribuido en el lejano sur de Chile al surgimiento de una poesía de valoración étnica y pluricultural. ${ }^{29}$

${ }^{28}$ Grínor Rojo, Critica del exilio (ensayos sobre literatura latinoamericana actual) (Santiago, Chile: Ediciones Pehuén, 1989) 45-46.

${ }^{29}$ Respecto a las tendencias dentro de la gran cantidad de poesía publicada en Chile desde 19731989, nosotros en nuestro libro de 1987, La joven poesía chilena..., 11-14, sugerimos alli la necesidad de estudiar las distintas tendencias en la gran y heterogénea producción post-1973. Iván Carrasco es el primero que realiza esto en "Poesía chilena de la última década (1977-1987)", Revista Chilena de 
La última conclusión es que el pastiche de Figueroa, la organización del texto de Mardones, algunos textos de Riedemann, no hay ninguna duda de que son asombrosamente parecidos en su forma y contenido al pastiche post-moderno de las verdaderas sociedades post-industriales. Tiene este pastiche - siguiendo la definición de Jameson- su misma construcción del montaje, su misma polifonía de voces y sus mismas referencias intertextuales de variadas fuentes: preferentemente las referencias entremezcladas de la llamada alta cultura y las referencias del mundo creado por la cultura de masas que en el pastiche post-moderno son las más dominantes, específicamente la de la sofisticada industria cultural. Incluyéndose también en este pastiche una gran diversidad multicultural y/o cultura de los márgenes: la cultura lumpen, la de las minorías étnicas, la escritura femenina, la cultura homosexual, la cultura urbana/ marginal/ heterogénea/ transnacionalizada, la cultura rural. Pero la diferencia fundamental es que la función de ese artefacto-pastiche, producido en la región de una provincia de un país sudamericano, no parece ser la imitación pura ni el rechazo dogmático de esa invasión ni tampoco, por otro lado, parece continuar ninguna condición nostálgica ni a-histórica tan dominante en el pastiche realmente postmoderno, sino re-codificar, re-apropiar, re-procesar críticamente una complejidad de imágenes altamente transnacionalizadas, provenientes de espacios y condiciones de vida realmente post-modernas que se insertan en sociedades profundamente fragmentadas y con visibles rasgos semi-modernos o pre-modernos de existencia. Y ésa sería una de las manera más correctas de entender lo "postmoderno" en América Latina según las últimas reflexiones más serias sobre el problema. ${ }^{30}$

Por eso no resulta extraño entonces que sean los jóvenes poetas de la provincia o del lejano sur —donde la condición larica sí resulta ahora objetivamente amenazada $a^{31}$ - y no tanto los de la capital, quienes mejor se estén dando cuenta de este interesante contraste provocado por la modernidad neoliberal, o el nuevo proceso extremo de la modernización del capitalismo transnacional en América Latina, incorporando así una nueva temática a la poesía chilena que quizás vaya a ser la dominante en este fin de siglo.

Nueva lírica chilena que semejante a la muy reciente producción de los jóvenes artistas de las dos Alemanias reunidas en 1991 parecen presagiar, entre diferencias y parecidos, el

Literatura 33 (abril 1989), 31-46. También Soledad Bianchi, trabajo leído (inédito), "Poesía chilena 1973-1991" en Nueva York, Americas Society, mayo 14, 1991. Y Grínor Rojo, trabajo inédito, "Nota sobre casi veinte años de literatura chilena (1973-1991)", leído en la Universidad de Maryland, 1-3 de diciembre, 1991. Carrasco también señala la tendencia etnocultural: "existe un grupo de poetas que no puede ser clasificado como neovanguardistas ni testimoniales (Carlos Trujillo, Clemente Riedemann) ... se percibe la lenta configuración de un nuevo y singular tipo de poesía etnocultural, característico de la zona sur de Chile", 41.

30 "Re-codificar", "re-apropiar" o "re-procesar" son otros términos para significar el mismo concepto de "respuestas-estéticas-ideológicas". Este último concepto es acuñado por Hugo Achugar y retomado por George Yúdice como hemos explicado en nuestra nota 5. Por otro lado, García Canclini nos parece que deja bien claro el problema cuando señala: "Es evidente que en América Latina la discusión no es apenas entre modernidad y postmodernidad. En una región donde lo moderno nunca llegaron del todo ni a todos ... lo que suele llamarse 'tradicional' o 'premoderno' debe ocupar un papel clave en el análisis de modernidad y postmodernidad", 43.

${ }^{31}$ Véase nuestra nota 19. 
nuevo futuro bajos los nuevos regímenes socialdemócratas del lejano sur de América Latina y del lejano Este europeo (incluida la ex-Unión Soviética), todos juntos ahora en el Nuevo Orden Norte-Sur del mundo. ${ }^{32}$

${ }^{32}$ En la revista del New York Times, New York, abril 7, 1991, se decía: "En los meses recientes, un grupo de jóvenes artistas del Este y del Oeste, apoyados por la ciudad, han producido una serie de trabajos artísticos relacionados con los problemas de la división. La mayoría están hechos en lugares públicos. Uno de ellos, cerca de Potsdamerplatz, está hecho de una abandonada torre de vigilancia, un símbolo de la opresión al viejo-estilo. En la parte alta de concreto de la torre, el artista instaló un inmenso y rotativo emblema en una suave luz azúl neón: la inconfundible estrella de la Mercedes Benz. Símbolo donde el artista parece decirnos que estamos ahora ante una nueva forma de opresión." (La traducción es nuestra). 